Published in final edited form as:

Addiction. 2008 December ; 103(12): 1937-1938. doi:10.1111/j.1360-0443.2008.02408.x.

\title{
Exposure to Alcohol Use in Movies: Future Directions
}

\author{
Sonya Dal Cin ${ }^{1}$, Keilah A. Worth ${ }^{2}$, Madeline A. Dalton ${ }^{3,4}$, and James D Sargent ${ }^{2,3}$ \\ ${ }^{1}$ Department of Communication Studies, University of Michigan \\ ${ }^{2}$ Norris Cotton Cancer Center, Dartmouth Medical School, Lebanon, NH, USA \\ ${ }^{3}$ Department of Pediatrics, Dartmouth Medical School, Lebanon, NH, USA \\ ${ }^{4}$ Hood Center for Families and Children, Dartmouth Medical School, Lebanon, NH, USA
}

\begin{abstract}
We would like to thank our colleagues for their thoughtful commentaries on our study of alcohol depictions in movies and levels of exposure to these depictions among youth in the United States.[1] In addition to providing an international perspective on our work, our colleagues rightly call for evaluations of the psychological and behavioural results of such exposure, and an understanding of the social and psychological processes that underlie such effects. We are happy to report that longitudinal studies investigating the effects of movie alcohol exposure on alcohol use over time are underway, and several articles are in press in various journals.[2-6] These studies assess the relation between exposure to alcohol use in movies and several outcomes, including onset of alcohol use, level of use, and abuse of alcohol Also included are comprehensive meditational analyses testing several potential psychosocial mediators including attitudes, expectancies, and norms about alcohol and alcohol users.
\end{abstract}

We agree that the nature of alcohol depictions may very well matter for outcomes, and look forward to experimental and quasiexperimental studies testing the impact various specific portrayals (e.g., alcohol paired with social success vs. negative consequences of alcohol use) might have on individuals' attitudes, norms, and expectancies. However, we note also that the published research to date show a fairly large main effect for general exposure levels without subcategorizing the exposure.[4,5,7]

It is understandable that movie alcohol depictions are seen as analogous to alcohol advertising - to the extent that brand appearances are paid for by alcohol manufacturers, they are indeed advertisements. Were alcohol marketing expenditures reported to governmental agencies (just as tobacco marketing expenditures in the US are reported to the Federal Trade Commission), the extent to which such appearances are paid advertisements could be more readily determined. However, we are also mindful that viewers likely approach movies quite differently than commercials, and this difference may have important implications for persuasion. [8] There are several potential differences, but the most straightforward may be the viewer's awareness of persuasive intent on the part of the communicator.[9] An individual who sees a beer commercial on television is aware that it is an advertisement paid for by the manufacturer, and this awareness may result in more critical scrutiny and counterarguing of the message. In contrast, an individual seeing a character drink a particular brand of beer in a movie may not recognize that this has been paid for by the manufacturer, resulting in a decreased likelihood that the message will be defended against or counterargued. It may be that story-based messages are even more powerful than traditional advertising, and we look forward to research testing this possibility.

Finally, we observed a striking racial disparity in exposure to movie alcohol depictions among our participants in the United States. As our colleagues pointed out, cultural and 
media contexts likely play a very important role in the adoption and escalation of alcohol use among young people. We look forward to cross-cultural research examining the role of media within diverse societies.

\section{References}

1. Dal Cin S, Worth KA, Dalton MA, Sargent JD. Youth Exposure to Alcohol Use and Brand Appearances in Popular Contemporary Movies. Addiction. 2008

2. Dal Cin S, Worth KA, Gerrard M, Gibbons FX, Stoolmiller M, Wills TA, Sargent JD. Watching and drinking: Expectancies, prototypes, and peer affiliations mediate the effect of exposure to alcohol use in movies on adolescent drinking. Manuscript under review.

3. Hanewinkel R, Morgenstern M, Tanski SE, Sargent JD. Longitudinal study of parental movie restriction on teen smoking and drinking in Germany. Addiction 2008;103(10):1722-30. [PubMed: 18821879]

4. Hanewinkel R, Tanski SE, Sargent JD. Exposure to alcohol use in motion pictures and teen drinking in Germany. Int J Epidemiol 2007;36(5):1068-77. [PubMed: 17586537]

5. Hanewinkel R, Sargent JD. Longitudinal Study of Exposure to Entertainment Media and Alcohol Use among German Adolescents. Pediatrics. In press.

6. Wills TA, Sargent JD, Gibbons FX, Gerrard M, Stoolmiller M. Movie Exposure to Alcohol Cues and Adolescent Alcohol Problems: A Longitudinal Analysis in a National Sample. Psychol Addict Behav. In Press.

7. Sargent JD, Wills TA, Stoolmiller M, Gibson JJ, Gibbons FX. Alcohol use in motion pictures and its relation with early-onset teen drinking. J Stud Alcohol 2006;67:54-65. [PubMed: 16536129]

8. Dal Cin, S.; Zanna, MP.; Fong, GT. Narrative persuasion and overcoming resistance. In: Knowles, ES.; Linn, JA., editors. Resistance and Persuasion. Mahwah, NJ: Lawrence Erlbaum Associates; 2004. p. 175-91.

9. Petty RE, Cacioppo JT. Effects of Forewarning of Persuasive Intent and Involvement on Cognitive Responses and Persuasion. Pers Soc Psychol B 1979;5(2):173-6. 